\title{
Sound localization and word discrimination in reverberant environment in children with developmental dyslexia
}

\author{
Localización sonora y discriminación de palabras en ambientes reverberantes en niños \\ con dislexia del desarrollo
}

Wendy Castro-Camacho', Yolanda Peñaloza-López1, Santiago J. Pérez-Ruiz², Felipe García-Pedroza³, Ana L. Padilla-Ortiz², Adrián Poblano', Concepción Villarruel-Rivas ${ }^{4}$, Alfredo Romero-Díaz', Aidé Careaga-Olvera ${ }^{5}$

\begin{abstract}
Objective: Compare if localization of sounds and words discrimination in reverberant environment is different between children with dyslexia and controls. Method: We studied 30 children with dyslexia and 30 controls. Sound and word localization and discrimination was studied in five angles from left to right auditory fields $\left(-90^{\circ},-45^{\circ}, 0^{\circ},+45^{\circ},+90^{\circ}\right)$, under reverberant and no-reverberant conditions; correct answers were compared. Results: Spatial location of words in no-reverberant test was deficient in children with dyslexia at $0^{\circ}$ and $+90^{\circ}$. Spatial location for reverberant test was altered in children with dyslexia at all angles, except -90 ${ }^{\circ}$. Word discrimination in no-reverberant test in children with dyslexia had a poor performance at left angles. In reverberant test, children with dyslexia exhibited deficiencies at -45, $-90^{\circ}$, and $+45^{\circ}$ angles. Conclusion: Children with dyslexia could had problems when have to locate sound, and discriminate words in extreme locations of the horizontal plane in classrooms with reverberation.
\end{abstract}

Keywords: dyslexia, reverberation, sound location, word discrimination.

\section{RESUMEN}

Objetivo: Comparar localización de sonidos y localización-discriminación de palabras bajo reverberación y sin reverberación en niños disléxicos y controles. Método: Estudiamos 30 niños disléxicos y 30 controles, pareados por edad. La localización sonora y discriminación a palabras fue estudiada en cinco ángulos horizontales en los campos izquierdo y derecho $\left(-90^{\circ},-45^{\circ}, 0^{\circ},+45^{\circ},+90^{\circ}\right)$, bajo reverberación y sin reverberación; las respuestas correctas fueron comparadas Resultados: La localización sonora sin reverberación fue deficiente en niños disléxicos a $0^{\circ} y+90^{\circ}$. La localización bajo reverberación falló en niños disléxicos en todos los ángulos, excepto -90. Durante la discriminación a palabras, sin reverberación, los niños disléxicos fallaron en ángulos izquierdos. En la prueba reverberante, los niños disléxicos fallaron a $-45^{\circ},-90^{\circ}$ y $+45^{\circ}$. Conclusion: Los niños con dislexia pueden tener problemas cuando tienen que localizar sonidos y discriminar palabras en las localizaciones extremas del plano horizontal en salones de clases típicos con reverberación.

Palabras clave: dislexia, reverberación, localización sonora, discriminación de palabras.

Developmental dyslexia (DD) is an alteration in learning to read in otherwise healthy children. DD has a prevalence of $6 \%-13 \%$ in school-age children ${ }^{1}$, thus is one of the major public health and educational concerns, specially in underdeveloped countries. DD has been related to alterations of auditory perception and, some studies have related DD with central auditory processes alterations ${ }^{2}$.
Auditory localization (AL) consists in the spatial identification of the sound source, while auditory discrimination $(\mathrm{AD})$ is defined as the ability of recognizing the features of an auditory stimuli ${ }^{3}$. Both processes are part of the central auditory processing functions and are of great importance in the teaching-learning process in academic activities of school age children. AL and AD are influenced by

\footnotetext{
${ }^{1}$ National Institute of Rehabilitation, Laboratory of Central Auditory Alterations Research, Mexico City, Mexico; ${ }^{2}$ National University of Mexico, Center of Applied Sciences and Technological Development, Mexico City, Mexico;

${ }^{3}$ National University of Mexico, School of Medicine, Department of Familial Medicine, Mexico City, Mexico;

${ }^{4}$ National Institute of Rehabilitation, Department of Pathology of Language, Mexico City, Mexico;

${ }^{5}$ National Institute of Rehabilitation, Department of Psychology, Mexico City, Mexico.

Correspondence:Adrián Poblano; Calzada México-Xochimilco 289, Col.Arenal-Guadalupe, Deleg. Tlalpan, 14389; México City, México; E-mail:drdislexia@yahoo.com.mx Conflict of interest: There is no conflict of interest to declare.

Received 14 October 2014; Received in final form 23 November 2014; Accepted 12 December 2014.
} 
reverberating characteristics of sound and voices within a typical classroom. High reverberating levels may modify the spectral sound characteristics, speech intelligibility that may affect features of oral message ${ }^{4,5}$. Thus, may be related to premature attention fatigue, and to low school performance of students $6,7,8,9$.

Binaural hearing refers to the fact of use both ears. This is used by humans in order to find the direction from which the sound comes. Spherical coordinate system is used to define direction of sound sources in relation with the listener's head position and orientation. There are three planes of sound orientation: horizontal (azimuthal), frontal, and median. When sound passed through outer, middle and inner ear, auditory signal is serially processed in different neuronal nuclei along auditory pathway in brainstem until reach the auditory cortex. Processing of sound stimuli is different if is administered mono- or bi-aurally. For example, Fujiki et al., observed that signals for bi-aural localization are processed before those coming only from mono-aural source, and that the cortical processing exhibiting preference of the contra-lateral hemisphere to the auditory localization ${ }^{10}$. The horizontal angle for faster perception to the sound was $0^{\circ}$. In the horizontal plane, bi-aural processing of the sound depends mainly, on the Interaural time difference (ITD), but frequencies $>3,000$ Hertz (Hz) may show the head shadow effect, that modifies $\operatorname{ITD}^{11,12}$.

In mammals, the first neuron of the auditory pathway in brainstem is located in the Cochlear nuclei, which is engaged with spectral analysis of sound, because receives only ipsilateral inputs from the Cochlea. Analysis of ITD is performed for first time in the Superior olivary complex in pons; here, the medial nuclei is linked with the loudness analysis, while spatial laterality of sound is identified in lateral nuclei ${ }^{11,13}$. Other important neuronal nuclei for auditory localization is the inferior colliculus in midbrain, which processes characteristics such as: duration, loudness, frequency, spatial domain, amplitude modulation, bi-aural interactions, and the close of phase among others ${ }^{13}$. Neurons in the medial geniculate body and other auditory areas in the cortex are engaged in spatial localization of sound. Ventral portion of the medial geniculate body has cells with sensitivity to ITD, and to interaural intensity difference (IID), both features are important to determine the position of sound sources in horizontal plane $^{12}$. At last, auditory inputs arrive to primary hearing cortex in the Superior temporal gyrus, for further analysis.

Functional magnetic resonance imaging (fMRI), and positron emission tomography (PET) studies performed in young adults disclosed relevant information to understand how brain locate and recognize the sound. It was observed that both functions are processed in parallel, but in different cortical regions; the posterior parietal and frontal cortex are related to sound localization, but they are not related to sound recognizing; sound recognizing is analyzed in the Superior temporal gyrus and inferior frontal cortex ${ }^{3}$.
In the medial geniculate body of subjects with DD, researchers had observed by means of post mortem studies, decreased number of neurons in the left thalamus when compared with the right. Authors suggested that this fact was related with an abnormal auditory processing in children with $\mathrm{DD}^{14}$. Moreover, there are a possible relationship among abnormal asymmetry and lower reading comprehension. In the case of inverted frontal asymmetry, investigators reported higher frequency of word decoding difficulties. It has been postulated that subjects with DD present abnormal maturational asynchrony in cortical hemisphere functions related to early reading learning stages. Children with DD have alterations in sound perception, auditory laterality, spatial orientation, and word phonological processing. Difficulties may become higher in noisy environments ${ }^{15}$. This kind of dysfunctions shown a significant correlation between phonological abilities and learning to read ${ }^{16}$.

Reverberation is the persistence of sound after the original sound production stops. Alterations of auditory information localization, in reverberant environment may influence a wide range of communication processes of children in classrooms ${ }^{17}$. With the objective to obtain an optimal percentage of adequate speech intelligibility in the classroom, noise levels must be controlled, and thus time of reverberation (TR) must be adequate ${ }^{18,19}$.

Standard classroom dimensions in many countries, is around $6 \times 8 \mathrm{~m}$. Trombetta-Zannin and Zanardo-Zwirtes reported that typical classrooms from public schools from different countries, such as: Brazil, Germany, United Kingdom, Japan, and United States of America, have identical measurements, producing a reverberation time of $0.4 \mathrm{sec}^{8}$.

Our objective was to evaluate if spatial word localization and recognizing, are influenced by the reverberant condition of $0.4 \mathrm{sec}$ among children with DD, when compared their performance with a group of healthy control children (CC), and to identify if some azimuthal locations from left or right auditory hemi-fields, presented more difficulties than others in the task.

\section{METHOD}

\section{Subjects}

A highly selected group of Mexican children with DD were chosen and compared with a group of healthy $\mathrm{CC}$ of the same age and socio-economic strata. We included subjects with specific DD as recommended by the Diagnostic and Statistical Manual of Mental Disorders (version-IV, American Psychiatry Association). A definition of DD was considered when reading and word spelling in a child does not develop, or develop with greater difficulty than their peers, despite an adequate socio-economic environment and absence of neurological alterations. Thirty children ( 25 males) with dyslexia met the following inclusion criteria: age between 7 and 11 years; normal 
neurological examination; index of visual acuity of $\geq 20 / 20$ in the Snellen visual chart or corrected acuity by glasses; normal pure-tone audiometry and tympanometry; adequate familial environment; belong to a middle socio-economic stratum, and normal result on the Wechsler intelligence scale for childrenrevised version ( full scale $>90$ ). No patients demonstrated attention deficit disorder, epilepsy, mental retardation, cerebral palsy, psychiatric disorders or other neurological signs, congenital malformations, or phoniatric alterations. Children with DD had an average of one year in speech therapy and their academic score average was 7.7 (range 6-9). The group of CC was comprised of 30 healthy children from public schools, age-matched, from same socio-economic stratum, each of the control subjects read at current school grade level or better ( full scale $\geq 90$ ). No CC demonstrated evidence of neurological, ocular, hearing, genetic, speech, or psychiatric disorders; moreover, they all exhibited good scholarly performance (academic average, $>8$ of 10 points). All patients and controls subjects were right-handed. The protocol was approved by the Institutional Ethics and Research committee, and parents of children with DD and CC signed informed consent forms according to Declaration of Helsinki.

\section{Reverberant and no-Reverberant Tests}

Recording of sounds and words for Reverberant test (RT) and no-Reverberant test (nRT) was performed at the Laboratory of Acoustics and Vibration from the National University of Mexico. Binaural recordings were carried-out into anechoic chamber at different azimuth angles from $-90^{\circ}$ to $+90^{\circ}$ in steps of $45^{\circ}$, where a negative sign refers to the left-auditory hemi-field and a positive sign to the right side. The speech signals were binaurally recorded with a head and torso manikin (Brüel \& Kjaer type 4128, Copenhagen, Denmark) ${ }^{20}$. Speech material consisted of 5 different lists of words, with 20 bi-syllable phonetically balanced Spanish words, commonly used in everyday conversation, speech was produced by female speaker ${ }^{21}$. In order to obtain a reverberated speech signal, recorded speech was convolved with an artificial reverberant impulse. The reverberation time was set to $0.4 \mathrm{sec}$.

\section{Procedure}

Subjects were tested in a sound-proof chamber comfortably seated in a chair. Children received bi-aurally and at random, stimuli by means of speakers located a $-90^{\circ}$, $-45^{\circ}, 0^{\circ},+45^{\circ}$ and $+90^{\circ}$ (Figure). Stimuli was delivered by an Audiometer (Amplaid 460 IEC645/Type, Milano, Italy); earning level (in decibels $(\mathrm{dB})$ re; American National Standards Institute SR3.6-ISO 389) was at $50 \mathrm{~dB}$ sound level above the hearing patient threshold at 1,000 Hertz. Children received previously an assay of five words at $0^{\circ}$ for practice localization. Time between stimuli was $500 \mathrm{msec}$ for both test. At the end of each trial, children must located stimuli in a picture (Figure). Each angle point was scored for location as a correct or a wrong answer. In the same way, word discrimination was qualified as the percentage of right answers for each place for both: RT and nRT.

\section{Statistical analysis}

We calculated average and standard deviation (SD) of quantitative data, and frequencies and percentages of qualitative variables. We used the Student t-test for comparison in quantitative variables. We compared averages differences with the U of Mann-Whitney test, in those variables without Gaussian distribution. We used the Test of linearity to search for differences in distributions in ordinal variables, and $X^{2}$ test for comparison in percentages distribution. Moreover, we performed a Multivariate analysis using sounds localization and word discrimination as dependent variables, DD condition as the fixed factor, and taking into account visual acuity and intelligence quotient (IQ) as covariates. For multiple calculations we used the Bonferroni correction technique. Significance level to accepted differences for calculations was $\mathrm{p} \leq 0.05$.

\section{RESULTS}

\section{Overall data}

Data from demographic variables and sensory performance of groups of children with DD and CC are presented in Table 1. We found significant differences among groups in visual acuity, hearing thresholds, and intelligence quotients between groups of children with DD and CC, despite values were within normal range.
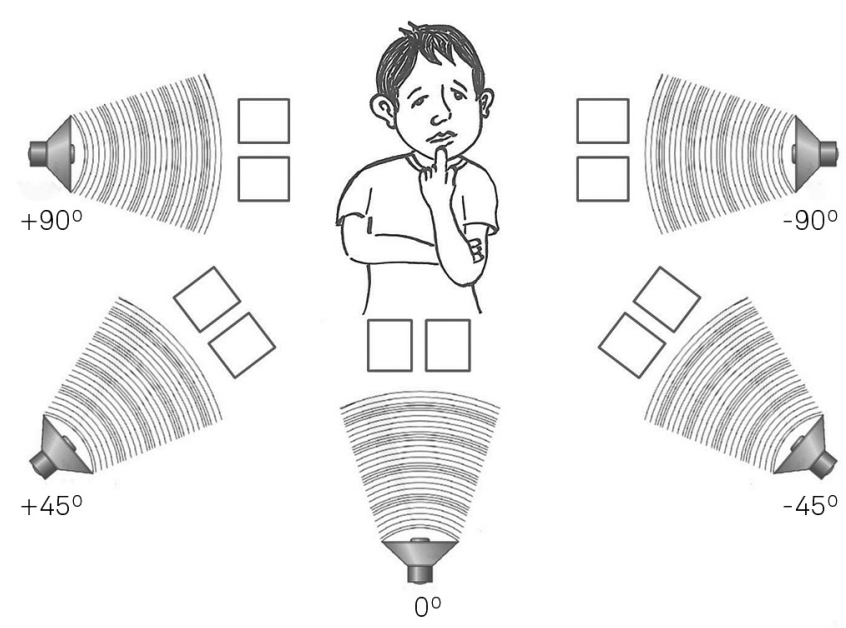

Right side

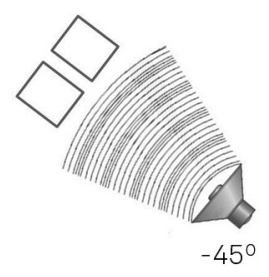

Figure. Map of localization of sound sources for our study at different azimuth angles from $-90^{\circ}$ to $+90^{\circ}$ in steps of $45^{\circ}$, where a negative sign refers to the left-hand and a positive sign to the right-hand side. After stimulation, children marked in the correspondent square of each site for locate each stimuli in a similar picture. 


\section{Auditory localization}

For nRT, children with DD had in general a low performance of correct responses than CC. Comparisons showed significantly differences in $0^{\circ}$, and $+90^{\circ}$ locations (Table 2 ). In the RT, children with DD showed abnormal lower results than $\mathrm{CC}$ at $-45^{\circ}, 0^{\circ},+45^{\circ}$ and $+90^{\circ}$ locations (Table 3 ).

\section{Word discrimination}

In the nRT, children with DD exhibited significantly lower percentages in word recognizing task for stimuli presented at the left of their auditory field; $-45^{\circ}$ and $-90^{\circ}$ (Table 4). In the RT, in overall, children with DD showed significantly lower percentages of discrimination than CC. Percentages of discrimination at $-90^{\circ},-45^{\circ}$, and $+45^{\circ}$ locations were found with significant low values (Table 5).

\section{Multivariate analysis}

In analysis weighting visual acuity as a co-variable in nRT, we found a significant low value between subjects with DD for word discrimination $(F=232 ; d f=1,56$; $\mathrm{p}<0.001)$. In the RT, we disclosed a significant value between subjects when visual acuity was taken into account for word recognizing $(F=524 ; d f=1,56 ; \mathrm{p}<0.001)$. When IQ was taken into account, in word recognizing task in nRT, we found a significant difference between subjects $(F=6182 ; d f=$ 1,57; $\mathrm{p}$ 0.001). At last, we disclosed a significant difference

Table 1. Demographic data and auditory performance of children with developmental dyslexia (DD), and control children (CC).

\begin{tabular}{|c|c|c|c|}
\hline & Dyslexics & Controls & $p$ \\
\hline \multicolumn{4}{|l|}{ Gender } \\
\hline male & 26 & 25 & 0.50 Fisher's test \\
\hline female & 4 & 5 & \\
\hline Age (mounts) & $116 \pm 13$ & $119 \pm 14$ & 0.89 Mann-Whitney's test \\
\hline \multicolumn{4}{|l|}{ School grade $(n)$} \\
\hline $3^{\circ}$ & 7 & 7 & $0.97 X^{2}$ test \\
\hline $4^{\circ}$ & 11 & 8 & \\
\hline $5^{\circ}$ & 9 & 11 & \\
\hline $6^{\circ}$ & 3 & 4 & \\
\hline \multicolumn{4}{|l|}{ Vision } \\
\hline abnormal & 20 & 3 & 0.001 Fisher's test \\
\hline normal & 10 & 27 & \\
\hline \multicolumn{4}{|l|}{ Hearing threshold dB } \\
\hline right & $12.9 \pm 3$ & $11.3 \pm 2$ & $0.04 *$ Student t-test \\
\hline left & $12.8 \pm 3$ & $10.8 \pm 2$ & $0.01 *$ \\
\hline \multicolumn{4}{|l|}{ Tympanometry } \\
\hline abnormal & 3 & 0 & 0.11 Fisher's test \\
\hline normal & 27 & 30 & \\
\hline Intelligence quotient & $94.5 \pm 10$ & $104 \pm 13$ & $0.002 *$ Student t-test \\
\hline
\end{tabular}

Table 2. Right answers performance in localization of horizontal presentation of words in the no-Reverberant test in children with DD and CC.

\begin{tabular}{ccccc}
\hline Angle & Dyslexics & Controls & Test of linearity & $p$ \\
\hline-90 & 12 & 16 & 1.05 & 0.30 \\
-45 & 10 & 15 & 1.68 & 0.19 \\
0 & 22 & 33 & 9.07 & $0.003^{*}$ \\
+45 & 8 & 14 & 1.80 & 0.18 \\
+90 & 6 & 15 & 5.83 & $0.01^{*}$ \\
\hline
\end{tabular}

*Statistically significant.

Table 4. Percentage of right answers in word recognizing of horizontal presentation in the no-Reverberant test in children with DD and CC.

\begin{tabular}{ccccc}
\hline Angle & Dyslexics & Controls & $\boldsymbol{X}^{2}$ test & $\mathrm{p}$ \\
\hline-90 & $98.16 \pm 3.59$ & $100 \pm 0$ & 9.23 & $0.02{ }^{*}$ \\
-45 & $97.83 \pm 3.63$ & $100 \pm 0$ & 10.58 & $0.005^{\star}$ \\
0 & $98.83 \pm 2.84$ & $99.83 \pm 0.91$ & 3.26 & 0.19 \\
+45 & $99.16 \pm 2.01$ & $100 \pm 0$ & 2.06 & 0.35 \\
+90 & $99.50 \pm 2.65$ & $100 \pm 0$ & 3.15 & 0.20 \\
\hline *Statistically significant. & & &
\end{tabular}

Table 3. Right answers performance in localization of horizontal presentation of words in the Reverberant test in children with DD and CC.

\begin{tabular}{ccccc}
\hline Angle & Dyslexics & Controls & Test of linearity & $\mathrm{p}$ \\
\hline-90 & 10 & 15 & 1.68 & 0.19 \\
-45 & 8 & 20 & 9.48 & $0.002^{*}$ \\
0 & 22 & 28 & 4.24 & $0.03^{*}$ \\
+45 & 8 & 18 & 6.67 & $0.01 *$ \\
+90 & 4 & 18 & 13.83 & $<0.001^{\star}$ \\
\hline *Statistically significant. & & &
\end{tabular}

Table 5. Percentage of right answers in word recognizing of horizontal presentation in the Reverberant test in children with DD and CO.

\begin{tabular}{ccccc}
\hline Angle & Dyslexics & Controls & $\boldsymbol{X}^{2}$ test & $\mathrm{p}$ \\
\hline-90 & $98.83 \pm 2.84$ & $100 \pm 0$ & 13.46 & $0.001^{\star}$ \\
-45 & $98.16 \pm 3.59$ & $100 \pm 0$ & 9.23 & $0.02^{\star}$ \\
0 & $98.33 \pm 3.30$ & $99.66 \pm 1.26$ & 4.48 & 0.10 \\
+45 & $98.50 \pm 3.25$ & $100 \pm 0$ & 6.66 & $0.03^{\star}$ \\
+90 & $99.50 \pm 2.65$ & $100 \pm 0$ & 5.45 & 0.06 \\
\hline * Statistically significant. & & &
\end{tabular}


between subjects, in the IQ in word recognizing in the RT $(F=3705.19 ; d f=1,57 ; \mathrm{p}<0.001)$.

\section{DISCUSSION}

In the present research we compared some central auditory processing tasks: sound localization, and word discrimination, under reverberant and no-reverberant conditions in children with DD and CC. We disclosed that children with DD had more problems than CC, when they have to locate sound source and to discriminate words in no-reverberant condition. When children with DD are challenged with the same tasks in reverberant environments, performance of children with DD was even worse, such as can be found in a typical size of classroom.

Several reports indicated that into schools rooms, there are high noise levels, and that the majority of classrooms do not have an adequate acoustic architectural design to avoid excessive reverberation effects. These facts underline the need to develop tests for screening children with DD with difficulties to identify sound sources and word discrimination in reverberant environment. In this research, the RT amount of $0.4 \mathrm{sec}$, was selected because is in line with previous report ${ }^{8}$, suggesting that this is commonly found in classrooms of $250 \mathrm{~m}^{2}$, and may have significant deleterious effect on academic activities. Longer rooms could accept higher amounts of reverberance (0.6-0.9 sec).

In our study, we confirm importance of the incidence angle in horizontal plane (azimuthal) for psychoacustical performance. We showed that children with DD have also alterations in central hearing localization in $\mathrm{nRT}$ at $0^{\circ}$. Is recognized that the best orientation for a better discrimination was $0^{\circ}$, or in front of the child. This observation supports the tendency to set students with learning difficulties, in front of the teacher. This tendency was also reported for the visual system ${ }^{22}$.

For location in reverberant test, children with DD showed a higher amount of errors in all azimuthal locations, except at $-90^{\circ}$. Alteration for sound localization found at $-45^{\circ}$ may results from right Parietal lobe dysfunction, as suggested from data from other researcher ${ }^{23,24}$. Difficulties for localization were also found in positive angles which suggests a link with a left-hemisphere temporo-parietal alteration ${ }^{25,26}$.

Burke et al. commented that all signals locations, except those coming from $0^{\circ}$ of the sagittal plane, give cues for the interpretation of frequency and time order of arrive of inputs at the different auditory nuclei of the brainstem ${ }^{23}$. Additionally, the contra-lateral auditory cortex to the stimulated ear has an important role in auditory localization, such as disclosed in experiments with animals, and observations in humans. These researches conclude that bi-aural localization ability for the left auditory hemi-field is better than the right hemifield as a central auditory processing node for spatial auditory information ${ }^{27}$. Researchers concluded also that the biaural localization best abilities with a sound stimuli coming from the left hemi-field, link the right-hemisphere as the main primary processor of spatial information.

Data from this research underline alterations in $\mathrm{AL}$ and $\mathrm{AD}$ in children with DD. AL referred to cerebral hemisphere preference; $\mathrm{AD}$ is referred to relationship between subject to acoustic environment. Sound localization process (important for word perception) has been few studied in school and social environments. Sound discrimination has been more studied, for example, Montcrieff et al. carried-out observations of $\mathrm{AD}$ by means of fMRI in children with DD; they presented recordings of tales with discordant words and they observed that children with DD presented lower activation in left hemisphere, and a more symmetric inter-hemispheric activation ${ }^{28}$. Olivares-García et al. data are in line with these conclusions, showing that $\mathrm{AD}$ requires a functional symmetry among cerebral hemispheres in children with $\mathrm{DD}^{15}$. Dawes et al. studied temporal alterations in children with DD and with auditory processing disorder; authors found that temporal alterations were not a determining factor for central auditory alterations, and had not a direct impact in learning disability, however, children with auditory processing disorder had poor hearing quality in noisy environments such as in classrooms, with scholastic and social consequences ${ }^{29}$.

In the last decades, theoretical aspects of research of AL, and $\mathrm{AD}$ knowledge are in increase. One of the main issues is related to the dual theory of the "Where?" and "What?" of the auditory information processing ${ }^{25,30}$. Either function differ around 100 msec of latency, when it was studied by means of evoked potentials. Although the majority of researches had been performed in animals, some observations are under investigation in humans. The meta-analysis of Arnott et al. is very influential in this point ${ }^{26}$. Studies carried-out by fIRM confirm the information division processing, according to the fashion of the administrated stimuli. Researchers have proposed the existence of specific ventral and dorsal tracts that carry information to the auditory temporal area (what?), and to the parietal cortex (where?) respectively ${ }^{26}$.

If we take into account that in usual conditions of the classrooms in many countries are in similar conditions as in this study, we realize that reverberant condition is the daily school environment. The model in our study for word discrimination seems to set in evidence alterations found in children with $\mathrm{DD}$ for $\mathrm{AD}$ under reverberant conditions, as an excessive of sensory load for central auditory perception with important difficulties for word recognizing.

Children with DD had difficulties for word recognizing under reverberation in negative angles and $+45^{\circ}$, which means a predominantly a right, but also a left auditory hemi-field dysfunction. This was one of the most significant finding of our research, to show the increased difficulties of children with DD, when they have to face a task, that challenge a higher order perceptual network, with a predominance of participation of the neurons decoding stimuli in right cerebral hemisphere. In one study carried-out by Murphy-Ruiz et al., authors observed that although all psychoacoustics tests engaged both cerebral 
hemispheres, some abnormal tests were linked to right hemisphere processing ${ }^{24}$. Ligges et al. observed by means of fMRI and electroencephalography that children with DD used the right-hemisphere analogues areas to the posterior left-hemisphere language areas, to compensate the processing deficits ${ }^{31}$.

At last, multivariate analysis reveals that when visual acuity and IQ were taking into account as co-variables, we found that had a significant role in $\mathrm{AL}$, and $\mathrm{AD}$, despite the fact that both variables were within the normal range for age and gender for normal populations. For this reason, these variables were selected for a multivariate analysis. Further analysis is necessary to answer these questions.
In conclusion, our results suggested that children with DD have significant difficulties with AL of a sound source, and in $\mathrm{AD}$ for words, in the horizontal plane, in reverberant environments. We confirm that the better site for sound localization was at $0^{\circ}$, in both, children with DD and CC. Despite these facts, we observed a negative influence of reverberation in auditory left-side for word discrimination, suggesting a right-hemisphere perceptual auditory deficiency. These elements could be found in a typical classroom. Thus, more research using fMRI correlations and studying a large sample, weighting other variables such as pure-tone audiometry, and executive functions is need.

\section{References}

1. Shaywitz SE, Shaywitz BA, Fletcher JM, Escobar MD Prevalence of reading disability in boys and girls: results of the Connecticut Longitudinal Study. JAMA. 1990;264(8):998-1002. http://dx.doi.org/10.1001/jama.1990.03450080084036

2. Peñaloza-López Y, Poblano A, García-Pedroza F. Central auditory processing alterations in phonological dyslexia. In: Costa, A., Villalba, E, editors. Horizons in neuroscience research. New York: Nova Science; 2013. p. 123-34.

3. Alain C, Arnott SR, Hevenor S, Graham S, Grady CL. "What" and "where" in the human auditory system. Proc Natl Acad Sci USA. 2001;98(21):12301-6. http://dx.doi.org/10.1073/pnas.211209098

4. Dreossi RCF, Momenshon-Santos T. Noise and its interference over students in a classroom environment: literature review. Pró-Fono Rev Atual Cient. 2005;17(2):251-8. http://dx.doi.org/10.1590/S0104-56872005000200014

5. Woolner P, Hall E. Noise in schools: a holistic approach to the issue. Int J Environ Res Public Health. 2010;7(8):3255-69. http://dx.doi.org/10.3390/ijerph7083255

6. Kjellberg A. Effects of reverberation time on the cognitive load in speech communication: theoretical considerations. Noise Health. 2005;7(25):11-21.

7. Ramma L. Knowledge and attitudes of teachers regarding the impact of classroom acoustics on speech perception and learning. S Afr J Commun Disord. 2009;56:35-47.

8. Zannin PHT, Zwirtes DPZ. Evaluation of the acoustic performance of classrooms in public schools. Appl Acoust. 2009;70(4):626-35. http://dx.doi.org/10.1016/j.apacoust.2008.06.007

9. Klatte M, Lachmann T, Meis M. Effects of noise and reverberation on speech perception and listening comprehension of children and adults in a classroom-like setting. Noise Health. 2010;12(49):270-82. http://dx.doi.org/10.4103/1463-1741.70506

10. Fujiki N, Riederer KA, Jouskmäki V, Mäkelä JP, Hari R. Human cortical representation of virtual auditory space: differences between sound azimuth and elevation. Eur J Neurosci. 2002;16(11):2207-13. http://dx.doi.org/10.1046/j.1460-9568.2002.02276.x

11. Van Wanrooij MM, Van Opstal AJ. Sound localization under perturbed binaural hearing. J Neurophysiol. 2007;97(1):715-26. http://dx.doi.org/10.1152/jn.00260.2006

12. Lang AG, Buchner A. Relative influence of interaural time and intensity differences on lateralization is modulated by attention to one or the other cue.J Acoust Soc Am. 2008;124(5):3120-31. http://dx.doi.org/10.1121/1.2981041

13. Hernández-Zamora E, Poblano A. [The auditory pathway. Information integration levels and main neuro-trasmitters]. Gac Med Mex. 2014:150(5):450-60. Spanish.
14. Galaburda AM, Eidelberg D. Symmetry and asymmetry in the human posterior thalamus. II Thalamic lesions in a case of developmental dyslexia. Arch Neurol. 1982;39(6):333-6. http://dx.doi.org/10.1001/archneur.1982.00510180011002

15. Olivares-García MR, Peñaloza-López YR, García-Pedroza F, JesúsPérez S, Uribe-Escamilla R, Jiménez de la Sancha S. IIdentification of auditory laterality by means of a new dichotic digit test in Spanish, and body laterality and spatial orientation in children with dyslexia and in controls]. Rev Neurol. 2005;41(4):198-205. Spanish.

16. Mody M, Wehner DT, Ahlfors SP. Auditory word perception in sentence context in reading disabledchildren. Neuroreport. 2008;19(16):1567-71. http://dx.doi.org/10.1097/WNR.0b013e328311ca04

17. Picard M, Bradley JS. Revisiting speech interference in classrooms. Audiology. 2001;40(5):221-44. http://dx.doi.org/10.3109/00206090109073117

18. Bradley JS, Sato H. The intelligibility of speech in elementary school classrooms. J Acoust Soc Am. 2008;123(4):2078-86. http://dx.doi.org/10.1121/1.2839285

19. Neuman AC, Wroblewski M, Hajicek J, Rubinstein A. Combined effects of noise and reverberation on speech recognition performance of normal-hearing children and adults. Ear Hear. 2010;31(3):336-44. http://dx.doi.org/10.1097/ AUD.0b013e3181d3d514

20. Padilla-Ortiz AL. Application of binaural audio technology to improve sound quality in mobile communication systems Doctoral Thesis. School of Sciences, National University of Mexico. Mexico City; 2012.

21. Salinas G. Validation by means of acoustic index of voice material to measure intelligibility [Bachelor in Science Thesis]. School of Sciences, National University of Mexico. Mexico City; 2007.

22. López-Escribano C. [Contributions of neuroscience to the diagnosis and educational treatment of developmental dyslexia]. Rev Neurol. 2007;44(3):173-80. Spanish.

23. Burke KA, Letsos A, Butler RA. Asymmetric performances in binaural localization of sound in space. Neuropsychologia. 1994;32(11):1409-17. http://dx.doi.org/10.1016/00283932(94)00074-3

24. Murphy-Ruiz PC, Peñaloza-López YR, García-Pedroza F, Poblano A. Right cerebral hemisphere and central auditory processing in children with developmental dyslexia. Arq Neuropsiquiatr. 2013;71(11):883-9. http://dx.doi.org/10.1590/0004-282X20130172

25. Belin P, Zatorre RJ. "What" and "where" and "how" in auditory cortex. Nat Neurosci. 2000;3(10):965-6. http://dx.doi.org/10.1038/79890

26. Arnot SR, Binns MA, Grady CL, Alain C. Assessing the auditory dual-pathways model in humans. Neuroimage. 2004;22(1):401-8. http://dx.doi.org/10.1016/j.neuroimage.2004.01.014 
27. Sininger YS, Bhatara A. Laterality of basic auditory perception. Laterality. 2012;17(2):129-49. http://dx.doi.org/10.1080/1357650X.2010.541464

28. Moncrieff D, McColl RW, Black JR. Hemodynamic differences in children with dichotic listening deficits: preliminary results from fMRI study during a cued listening task. J Am Acad Audiol. 2008;19(1):33-45. http://dx.doi.org/10.3766/jaaa.19.1.4

29. Dawes P, Sirimanna T, Burton M, Vanniasegaram I, Tweedy F, Bishop DVM. Temporal auditory and visual motion processing of children diagnosed with auditory processing disorder and dyslexia. Ear Hear. 2009;30(6):675-86. http://dx.doi.org/10.1097/AUD.0b013e3181b34cc5
30. Leavitt MV, Molholm S, Gomez-Ramirez M, Foxe JJ. "What” and "where" in auditory sensory processing: a high-density electrical mapping study of distinct neural processes underlying sound object recognition and sound localization. Front Neurosci. 2011;5:1-15. http://dx.doi.org/10.3389/fnint.2011.00023

31. Ligges $C$, Ungureanu M, Ligges M, Blanz B, Witte $H$. Understanding the time variant connectivity of the language network in developmental dyslexia: new insights using Granger causality. J Neural Transm. 2010;117(4):529-43. http://dx.doi.org/10.1007/s00702-010-0367-x 